Anales de Geografía de la Universidad Complutense ISSN: 0211-9803

https://dx.doi.org/10.5209/aguc.79341

\title{
La cohesión social y el arraigo territorial en el turismo rural comunitario: caso localidad de Usme Bogotá-Colombia
}

\author{
Alba Ligia López Rodríguez ${ }^{1}$; Sergio Andrés López Rodríguez ${ }^{2}$ \\ Recibido: 9 de mayo del 2020 / Enviado a evaluar: 26 de septiembre del 2020 / Aceptado: 10 de diciembre del 2021
}

\begin{abstract}
Resumen. Un modelo de turismo rural comunitario sostenible es complejo, por lo que el objetivo de este estudio es valorar la influencia de factores como la cohesión social y el arraigo territorial en la localidad de Usme (Bogotá-Colombia), territorio con un significativo patrimonio natural y cultural. Se realiza un estudio documental para analizar experiencias nacionales e internacionales y un estudio de campo, mediante entrevistas semiestructuradas y observación directa sobre el terreno. Los resultados confirman que los factores mencionados son claves para el éxito de los emprendimientos turísticos.
\end{abstract}

Palabras clave: Turismo rural comunitario; cohesión social; arraigo territorial; desarrollo local.

\section{[en] Social cohesion and territorial roots in community rural tourism: case of the Usme location Bogotá-Colombia}

\begin{abstract}
A model of sustainable community rural tourism is complex, so the objective of this study is to assess the influence of factors such as social cohesion and territorial roots in the locality of Usme (Bogotá-Colombia), a territory with natural and cultural heritage very significant. A documentary study is carried out to analyze national and international experiences and a field study through semi-structured interviews and direct observation on the ground. The results confirm that the aforementioned factors are key to the success of the turism entrepreneurships.

Key words: Community rural tourism; social cohesion; territorial roots; local development.

1 Escuela de Ciencias Básicas, Tecnología e Ingeniería (ECBTI). Universidad Nacional Abierta y a Distancia (UNAD). Bogotá (Colombia).

E-mail: alba.lopez@unad.edu.co

2 Facultad de Ciencias Económicas, Administrativas y Contables. Universidad Libre Seccional Cali.

Cali (Colombia).

E-mail: sergioa.lopezr@unilibre.edu.co
\end{abstract}


[fr] Cohésion sociale et racines territoriales dans le tourisme rural communautaire: cas de l'emplacement Usme Bogotá-Colombie

Résumé. Un modèle de tourisme rural communautaire durable est complexe, donc l'objectif de cette étude est d'évaluer l'influence de facteurs tels que la cohésion sociale et les racines territoriales dans la ville d'Usme (Bogotá-Colombie), un territoire avec un patrimoine naturel important et culturel. Une étude documentaire est réalisée pour analyser les expériences nationales et internationales et une étude de terrain, à travers des entretiens semi-structurés et une observation directe sur le terrain. Les résultats confirment que les facteurs susmentionnés sont essentiels au succès des entreprises touristiques.

Mots clés: Tourisme communautaire rural; cohésion sociale; racines territoriales; développement local.

Cómo citar. Galimberti, C.; Jacob, N. (2021): La cohesión social y el arraigo territorial en el turismo rural comunitario: caso localidad de Usme Bogotá-Colombia. Anales de Geografía de la Universidad Complutense, 41(2), 3655-387.

Sumario. 1. Introducción. 2. Antecedentes teóricos y estado del arte. 2.1. Contexto del objeto y el problema de estudio. 2.2. Influencia de la cohesión social y el arraigo territorial en el turismo. 2.3. El turismo de naturaleza y su crecimiento. 3. Criterios metodológicos, hallazgos y resultados de la investigación. 3.1. Hallazgos de la revisión de fuentes documentales. 3.1.1. Sostenibilidad del territorio. 3.1.2. Potencial turístico. 3.2. Hallazgos del estudio de campo. 3.2.1. Instrumento de medición. 3.2.2. Resultados del estudio de campo. 3.2.3. Observación directa. 3.3. Propuesta del modelo de turismo rural comunitario para la localidad de Usme. 4. Conclusiones y consideraciones finales. 5. Referencias bibliográficas.

\section{Introducción}

En América Latina se ha dado un impulso importante a iniciativas de turismo de naturaleza, como una medida para cumplir con los Objetivos de Desarrollo Sostenible (ODS). Así, los investigadores desde varias disciplinas intentan identificar los factores de éxito o fracaso de las empresas turísticas nacientes, identificando la cohesión social como uno de los factores determinantes. Para el caso expuesto en este documento, además de la cohesión social se contempla el arraigo territorial, como fenómenos interrelacionados que influyen en el turismo rural comunitario (Nieto, 2013; Burgos, 2016; Kieffer, 2016; OMT, 1995).

Por lo que se refiere al territorio de Usme (localidad de Bogotá), éste posee características singulares por su fragilidad ambiental, apreciable patrimonio natural y cultural, cercanía al casco urbano de Bogotá, conflictos sociales por el acelerado poblamiento, conurbación y degradación de los recursos naturales. Por esto, el turismo rural comunitario se ha considerado como una alternativa para el cambio de uso del suelo, pero no se han logrado los resultados esperados con los emprendimientos implementados desde hace alrededor de una década. Sin embargo, varios estudios han mostrado resultados exitosos en el desarrollo sostenible de territorios rurales en países latinoamericanos como México y Costa Rica, entre otros y en algunos países de Europa (Ellis, 2011; Kieffer, 2016; Universidad Diego Portales, 2009).

En su estructura el presente artículo se distribuye en tres apartados. El primero, antecedentes teóricos y estado del arte, hace referencia al contexto del objeto de 
estudio, Localidad de Usme; también incluye los criterios de varios autores sobre la influencia de la cohesión social y el arraigo territorial en el turismo; luego, se hace mención sobre los antecedentes teóricos para el desarrollo del turismo de naturaleza desde un enfoque global, nacional y local y, finalmente, se analizan las políticas públicas en Colombia que favorecen el desarrollo del turismo y las oportunidades que se abren para fomentarlo en el marco del proceso de paz colombiano.

En el segundo apartado: criterios metodológicos, hallazgos y resultados de la investigación, se aborda la metodología y se exponen los hallazgos sobre los eventos de estudio, para finalizar con la propuesta del modelo de turismo rural comunitario que integre los eventos de estudio: cohesión social y arraigo territorial.

En el tercero y último apartado: conclusiones y consideraciones finales, se analizan los resultados relevantes y se exponen algunas recomendaciones.

\section{Antecedentes teóricos y estado del arte}

\subsection{Contexto del objeto y el problema de estudio}

La Localidad de Usme es la más extensa de las 20 localidades que tiene el Distrito Capital de Bogotá, según el Plan de Ordenamiento Territorial del año 2004. El 85\% (18.307 hectáreas) de su territorio es rural con vocación agrícola (42.9\%) y amplias zonas protegidas, por tener ecosistemas de páramo (42.1\%); el área urbana equivale al $10 \%$ del territorio (7 \% de suelo urbano y 3\% como área protegida por su interés arquitectónico) y el suelo de expansión (5\%) por ser la frontera con la metrópoli. De hecho, Usme es la entrada al Páramo de Sumapaz, considerado el más grande del mundo (Alcaldía Mayor de Bogotá, 2000, 2004; León, 2013). Así, desde el punto de vista ambiental, es un territorio estratégico para Bogotá para el abastecimiento de agua y como pulmón de la ciudad. Pero además de la riqueza natural, posee un atractivo patrimonio histórico legado desde la época prehispánica, la Colonia y la República.

Usme se ubica al suroriente de Bogotá colindando con el casco urbano de la metrópoli (con cerca de 8 millones de habitantes) por lo que representa un desafío para las autoridades, tanto distritales como locales, por los delicados problemas sociales, económicos y ambientales, que se han agudizado en las últimas décadas. Además, se presentan los mayores índices de pobreza, problema agravado por el crecimiento desordenado y sin planificar de la población que llega a cerca del 13\%, mientras que las localidades urbanas crecen alrededor del 5,5\% anual (León, 2013). Bajo estas circunstancias, los índices de violencia se ven fortalecidos, al igual que la delincuencia y el consumo de estupefacientes. El crecimiento inusual de la población del territorio tiene sus orígenes en la llegada de personas desplazadas o reinsertadas como consecuencia de la violencia que ha azotado al país desde hace más de medio siglo. Como se vislumbra, este fenómeno agudiza los problemas de falta de cohesión social y de arraigo, los cuales, a su vez, impactan negativamente la sostenibilidad del territorio. 
Como es de suponer, los conflictos por uso del suelo están a la orden del día y poco o nada se respetan las normas del Plan de Ordenamiento Territorial (POT), por lo que el panorama ambiental no es alentador debido al surgimiento de una industria minera de canteras para la extracción de arena, recebo y fabricación de ladrillos, materiales demandados por la creciente expansión urbana y por las necesidades de construcción en la ciudad de Bogotá. Esto empuja la frontera agrícola hacia tierras altas invadiendo áreas protegidas, con el consecuente deterioro del patrimonio natural y cultural (Alcaldía Mayor de Bogotá, 2007, 2010; León, 2013). En este escenario se han planteado alternativas de emprendimientos de turismo rural comunitario para mejorar la sostenibilidad social, ambiental y económica del territorio.

Las iniciativas de emprendimiento se han gestado por un grupo de mujeres campesinas oriundas del territorio y con un fuerte arraigo, con el apoyo de varias universidades (desde el año 2000), adecuando doce fincas para consolidar la Ruta Agroturística La Requilina ${ }^{3}$. Este proceso nace de la asociación de varias mujeres en la Corporación Mujer y Tierra, quienes han visto en el turismo rural comunitario una alternativa que permite detener el deterioro del patrimonio natural y cultural, generando opciones laborales. De manera que el acompañamiento a la comunidad, por parte de la alcaldía, el IDT ${ }^{4}$, varias universidades, entre otras organizaciones, han incluido en el diseño de la Ruta Turística, la señalización, adecuación temática de las fincas, capacitación de los dueños como guías turísticos, diseño de estrategias de mercado y desarrollo de una página web. Sin embargo, dichos emprendimientos no han tenido los resultados esperados y solo esporádicamente se realizan visitas, normalmente promovidas por la alcaldía.

De esta realidad surge el interés de los autores de este artículo para investigar y acompañar a la comunidad, proceso iniciado en el año 2015. En la primera fase de la investigación, se propone un modelo de turismo sostenible integrador que involucra a los actores: comunidad, empresas, sector público y academia. Aquí se identifica que una de las principales causas de la ausencia de turistas es la seguridad y la insatisfacción del visitante, asociados a la poca participación de la comunidad débilmente cohesionada y sin arraigo, lo que da origen a la segunda etapa de la investigación orientada a valorar la influencia de estos aspectos para la viabilidad del turismo rural comunitario.

\subsection{Influencia de la cohesión social y el arraigo territorial en el turismo}

Etimológicamente el vocablo cohesión proviene del latín cohaesum (adherirse o reunirse) y en el contexto del territorio se refiere al sentido de pertenencia de una comunidad a un espacio geográfico lo cual se visualiza por el grado de consenso entre

\footnotetext{
${ }^{3}$ Proyecto de Ruta Agroturística en la vereda de La Requilina de la localidad de Usme. Apoyado por estudiantes universitarios (Universidad Minuto De Dios y Universidad Nacional) y por el Instituto Distrital de Turismo.

${ }^{4}$ Instituto Distrital de Turismo.
} 
los habitantes. Así en una sociedad justa e igualitaria, la comunidad comparte intereses comunes, se suplen las necesidades del colectivo generando un alto grado de cohesión y como lo afirma Camacho (2016, p. 135), "un hecho espacial tiene por efecto crear vínculos sociales entre habitantes, colectivos y asociaciones que ponen en marcha una acción colectiva con un fuerte principio espacial que se manifiesta a través del proceso de territorializacion"." Por su parte Kieffer (2016) y CEPAL (2007), reconocen que la cohesión social es un elemento clave para la organización colectiva y el éxito de los proyectos de turismo específicamente.

Con respecto al arraigo territorial, se le considera una variable estrechamente relacionada con la cohesión social y se entiende como la identidad y pertenencia: "se puede establecer una gradación entre 'ser de' (sentido de procedencia), 'sentirse de' (sentido de pertenencia) y 'ser fiel', 'ser leal', 'amar a' (sentimiento de comunidad) un país, un territorio, una cultura, una ciudad" (Orduna, 2012, p.44). Desde el punto de vista etimológico el término arraigo se deriva de la expresión "echar raíces", es decir que la persona crea lazos culturales y afectivos que lo mantienen atado a un lugar determinado.

En este caso la permanencia del individuo en el espacio geográfico (hábitat) es voluntario y normalmente viene determinado por el origen de sus ancestros y sus allegados donde se comparten las mismas reglas o normas y principios o valores. El arraigo y la identidad social explican la relación del individuo con sus semejantes y con el medio ambiente construido. Para el caso del turismo, es determinante porque el individuo se identifica con su patrimonio cultural y natural, preservándolo, manteniéndolo y mejorándolo (CEPAL, 2007). En contraste, se ha visto la dificultad de integrar socialmente a personas que han sido desplazadas de su lugar de origen, sobre todo cuando este desplazamiento ha sido forzoso y como lo afirma Orduna (2012, pp. 43-44): "el desarraigo puede ser uno de los causantes de ciertas conductas asociales o antisociales que generan discriminación o exclusión social".

En relación con el orden político y jurídico, tanto la cohesión social como el arraigo al territorio se han incluido en el desarrollo de políticas públicas como factores de convivencia. Por ejemplo, desde 1992 con el nacimiento de la Unión Europea dicho tema es incorporado en el Tratado De Maastricht, que en esencia es "un protocolo de cohesión económica y social con el fin de promover un progreso económico y social equilibrado" (Universidad Diego Portales, 2009, p.6.). Así, surgen varias posturas conceptuales como se muestra en la figura 1.

Específicamente en los emprendimientos turísticos, la cohesión social y el arraigo territorial son indispensables para su éxito, como lo afirman Kieffer (2016), González \& Iglesias (2009) y Berger (2000), quienes concluyen que a la ausencia de estos factores se atribuyen los fracasos de iniciativas de turismo rural. Es decir, que el desarrollo de emprendimientos de turismo de naturaleza requiere el concurso de

\footnotetext{
${ }^{5}$ La geografía social define la territorialización como un doble movimiento de apropiación material e ideal de una porción de espacio por un grupo social (Camacho, 2016, p. 135).
} 
varios actores: comunidad, academia, empresas y Estado. La comunidad, porque el turismo impacta a todos los pobladores del destino (positiva o negativamente) y a su vez, la comunidad puede facilitar o impedir que los turistas logren la satisfacción y experiencias que buscan; el segundo actor (academia), porque con su ayuda se puede lograr la formación, sensibilización y concientización de los demás actores del turismo; el tercer actor (empresas), para el caso de Usme son microempresas, desarrollando servicios de calidad con procesos sostenibles y finalmente el Estado, como cuarto actor determinante para garantizar la seguridad, la infraestructura y el apoyo integral mediante políticas públicas.

Figura 1. Perspectivas de la cohesión social.

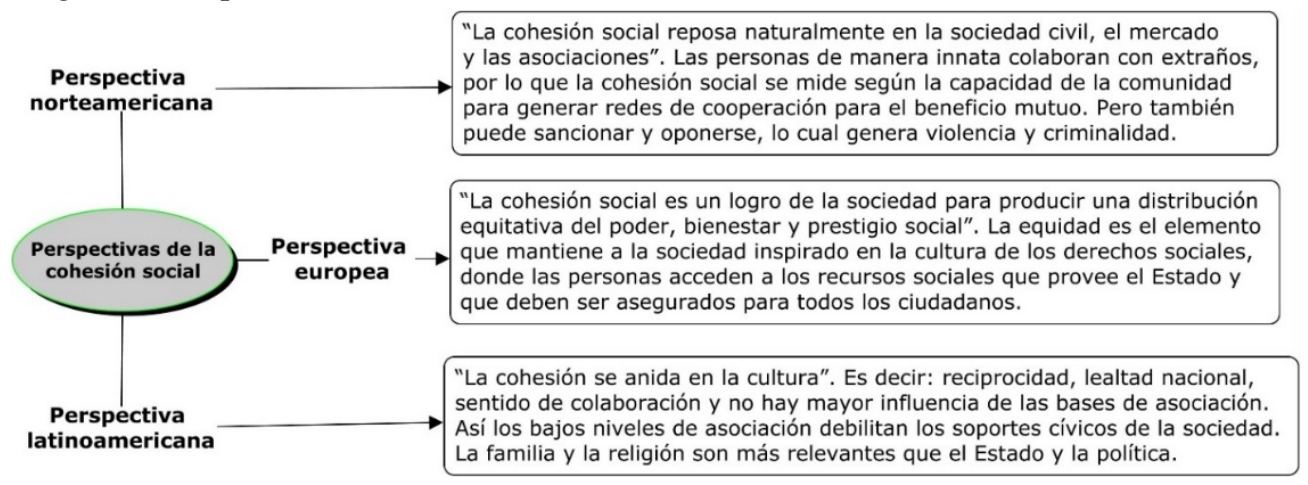

Fuente: Elaborado a partir de Universidad Diego Portales (2009, p.7).

Por otra parte, la cohesión social y el arraigo facilitan la aceptación y vinculación de la sociedad al turismo y específicamente Pérez-Ramírez y Zizumbo-Villarreal (2014, p. 25) afirman que el turismo es una alternativa de desarrollo sostenible y "es justamente el territorio el que puede afianzar, a partir del turismo, las condiciones de arraigo, cohesión social, reciprocidad y la formación de proyecto común para la solución a problemáticas compartidas".

\subsection{El turismo de naturaleza ${ }^{6}$ y su crecimiento}

El turismo rural tiene sus raíces en los conceptos de turismo y de espacio rural, por lo que no hay una definición única, como lo afirman Cebrián y García (2016). Los mismos autores reafirman que el turismo rural se basa en los recursos naturales y culturales de los espacios rurales, los cuales despiertan un interés creciente en las

${ }^{6}$ El turismo de naturaleza tiene como principal motivación es la observación y apreciación de la naturaleza y de las tradiciones o legados culturales. Contempla el ecoturismo, el turismo de aventura y el turismo rural (MinCIT, 2014). 
personas que desean conocer y disfrutar de estos espacios y al mismo tiempo surgen diferentes subtipos de turismo (turismo de aventura y turismo rural comunitario, entre otros). Sin embargo, en este artículo el turismo rural se considera una parte del turismo de naturaleza. Las ventajas del turismo de naturaleza sostenible es su capacidad para promover la conservación del patrimonio natural y cultural del territorio, además de generar fuentes económicas para los habitantes locales (Abellán \& González, 2016; Nieto, 2013).

Las bondades del turismo de naturaleza como actividad económica en cuanto a su capacidad de generar desarrollo integral y sostenible en los territorios es reconocido por varios autores, que argumentan, entre otras ventajas, la puesta en valor al patrimonio natural y cultural sin socavarlos, ser un dinamizador de procesos de conservación y restauración de dicho patrimonio y cambiar la vocación productiva del destino (cuando las actividades son depredadoras) especialmente en áreas protegidas (Fernández \& Martínez, 2017; Lorenzo \& Morales, 2014b; OMT, 1995; Pérez \& Zizumbo, 2014; Pérez, 2010).

Pasando al tema del desarrollo sostenible, en él se involucran tres dimensiones: social, económica y ambiental, las cuales se definieron desde 1992 en la Cumbre de la Tierra y con base en ellas se han establecido directrices y políticas públicas para el logro de los Objetivos de Desarrollo del Milenio (ODM), hasta 2015 y los Objetivos de Desarrollo Sostenible (ODS), hasta 2030 (OMT, 2015), con los cuales se pretende potenciar el Desarrollo Sostenible en todos los países (Asamblea General de Naciones Unidas, 2003; Pérez y Rojas, 2008). Luego, en el año 2000 el Pacto mundial ha incorporado una dimensión adicional al desarrollo sostenible ${ }^{7}$, la transparencia, dado que uno de los problemas de la sociedad actual es la corrupción. Así el Pacto Mundial busca que las empresas se comprometan con los ODS mediante el cumplimiento de 10 principios; dos, referidos a los Derechos Humanos; cuatro tratan sobre Estándares Laborales; tres se refieren al Medio Ambiente y uno aborda la Anticorrupción (ONU, 2015).

En relación con el turismo sostenible, en el marco de la Cumbre Mundial sobre Turismo sostenible +20 realizada en el año 2015 y el Código Ético Mundial para el Turismo, promulgado por la OMT (OMT, 2015; ONU \& UNWTO, 2001), se pide a todos los actores del turismo trabajar por la sostenibilidad, exhortándolos a emprender acciones para mejorar la conservación de la biodiversidad, el uso de fuentes energéticas renovables y no contaminantes y la erradicación de la pobreza. En este marco también se reconocen las bondades del turismo sostenible como una de las actividades económicas, por excelencia, que puede contribuir al desarrollo integral y sostenible de sitios apartados poseedores de un patrimonio natural y cultural que pueda convertirse en productos turísticos (Ellis, 2011; Langebeck y Beltrán, 2016).

\footnotetext{
${ }^{7}$ El Pacto mundial mediante 10 principios que cuentan con consenso universal y se derivan de las declaraciones de las Naciones Unidas en materia de recursos humanos y sostenibilidad. El pacto mundial vincula directamente a las empresas para que incorporen aspectos de sostenibilidad conducentes al cumplimiento de los Objetivos de Desarrollo Sostenible propuestos en la Agenda 2030 (ONU, 2015).
} 
Es así como el ecoturismo, turismo comunitario o agroturismo, se considera como una actividad colectiva que puede ofrecer alternativas para diversificar los ingresos en espacios rurales, favoreciendo a grupos vulnerables como mujeres, jóvenes y ancianos. Este incentivo económico anima a las comunidades a conservar y poner en valor su patrimonio natural y cultural, ya que los ingresos generados impulsan una cadena de acciones que conllevan a un impacto positivo, mejorando aspectos como la educación, la conciencia ecológica de los consumidores y residentes, lo que deriva en la conservación y muchas veces, regeneración de ecosistemas y el rescate de valores culturales (Global Sustainable Tourism Council [GSTC], 2015; López, 2013; Lorenzo y Morales, 2014; Pérez, 2010).

En lo que se refiere al comportamiento del turismo a nivel nacional, se resalta el crecimiento que ha tenido el sector, en el período 2012-2017, como se muestra en la gráfica 1. El crecimiento promedio de la llegada de viajeros del exterior a Colombia fue del $87 \%$ y el pico de crecimiento se dio en los pasos transfronterizos terrestres con el $103 \%$ entre 2012 y 2017 , seguido por la llegada de extranjeros no residentes con un $94 \%$.

Gráfica 1. Llegada de viajeros del exterior a Colombia, 2012-2017.

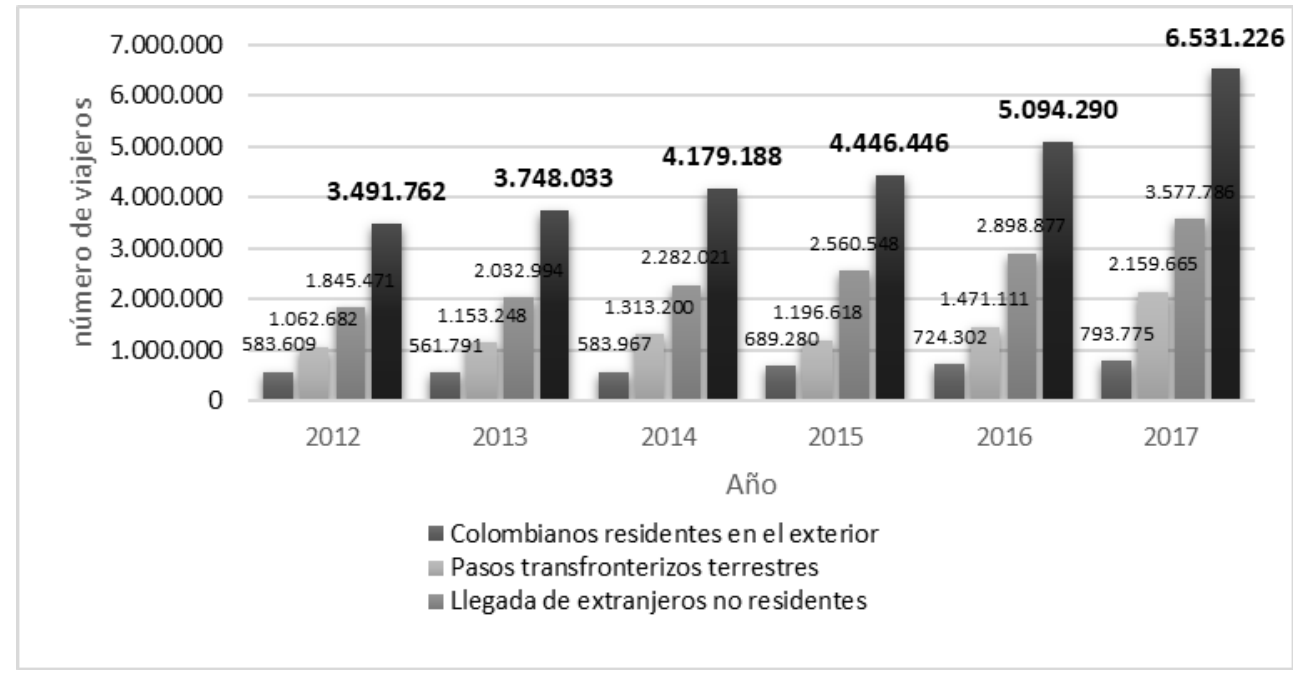

Fuente: Elaborado a partir de Procolombia (2018).

Por lo que se refiere al nivel local, Bogotá es el principal destino de extranjeros no residentes que llegan al país para asistir a eventos, por negocios y por otros motivos profesionales, como se muestra en la gráfica 2. 
Gráfica 2. Llegada de extranjeros no residentes para asistir a eventos, por negocios y motivos profesionales. Primer trimestre de 2018.

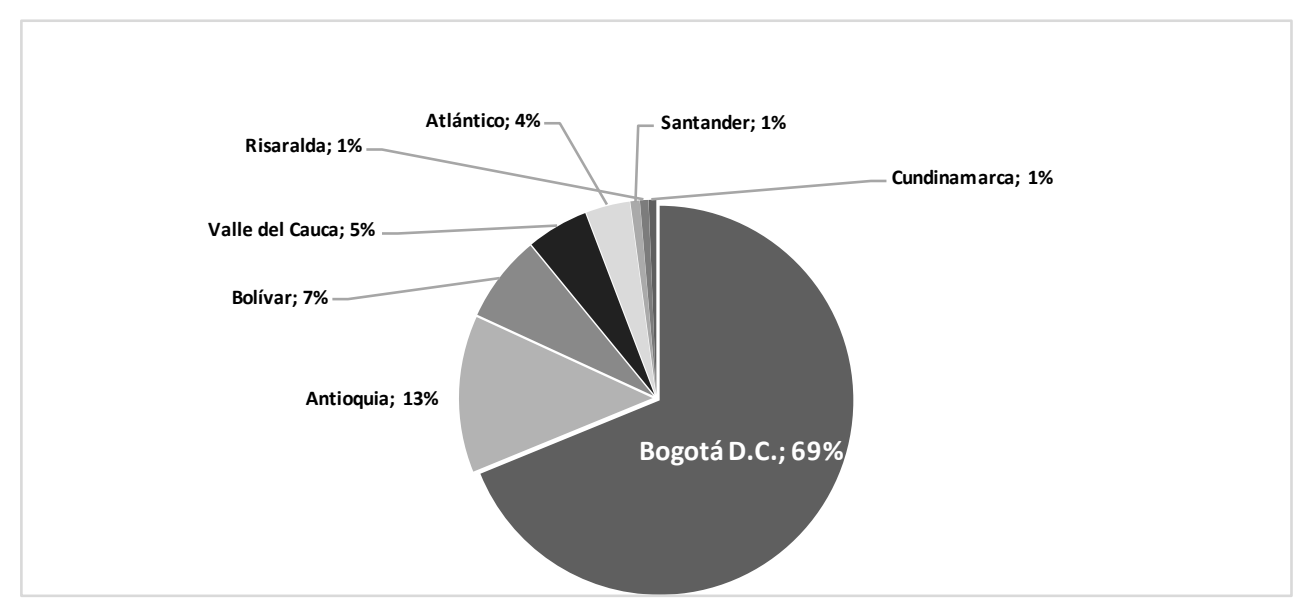

Fuente: elaborado a partir de Procolombia (2018, p.24.).

Este comportamiento puede explicarse por el impulso que se ha dado al turismo, desde la política pública en los ámbitos: nacional, regional y local, con alianzas entre el sector público, el sector privado y la academia, dentro del esquema UniversidadEmpresa-Estado (Ramírez y Valderrama, 2010). También se han aportado recursos importantes para impulsar proyectos productivos de impacto en las regiones; la política para posicionar la "marca país" a nivel internacional ha mostrado no solo la riqueza natural, sino el variado patrimonio cultural de las diferentes regiones del país y finalmente, el Programa de Transformación Productiva (PTP) - como política pública -, que ubica a tres sectores del turismo (turismo de naturaleza, turismo médico y turismo de bienestar) dentro de los 20 sectores que transformarán al país en los próximos años (Benavides, 2015; MinCIT, 2014; MinCIT, PTP y PROEXPORT, 2013; Procolombia, 2018).

Ahora bien, con el proceso de paz que adelanta Colombia y que ha dado otra cara al país en cuanto a la seguridad, se abre una serie de oportunidades para el turismo en regiones apartadas por la violencia (CERAC - PNUD, 2014; Alto comisiondo para la paz, 2016) por lo que el gobierno colombiano ha empezado a construir una cultura de paz a través del turismo, en el marco del post-conflicto y con el programa "Turismo, Paz y Convivencia", cuyo objetivo es integrar regiones afectadas por el conflicto armado de Colombia para que las comunidades logren mediante el turismo sostenible convertir los espacios de conflicto en territorios de paz, con el acompañamiento y apoyo de las entidades públicas, gremios, empresarios del turismo y la academia (Gómez, 2010; MinCIT, 2014). 
Por otra parte, el interés en el desarrollo y potencialización del turismo de naturaleza en Colombia, en particular, obedece a la dinámica internacional impulsada por la facilidad del transporte aéreo; el auge de las Tecnologías de la Información y la Comunicación (TIC), que han propiciado su crecimiento y por la ventaja comparativa que tiene el país como poseedor de una inmensa riqueza natural y paisajista, además de destacarse por su biodiversidad a nivel mundial (Benavides, 2015; Cerda y Leguizamón, 2005; López y López, 2018; MinCIT, 2014; MinCIT et al., 2013).

\section{Criterios metodológicos, hallazgos y resultados de la investigación}

La investigación desarrollada es proyectiva, como lo propone Hurtado (2012). Se parte del planteamiento de un Modelo de Turismo de Naturaleza que integralmente relacione las variables y actores para establecer una ruta de acción lógica y ordenada en el desarrollo de actividades de intervención en el territorio. Como se menciona anteriormente, el estudio exploratorio y descriptivo se ha venido trabajando desde 2015, donde en la primera etapa se propone el modelo de turismo y en la segunda etapa (origen de este documento) se vinculan-las variables identificadas como eventos determinantes para su éxito.

Por otra parte, el diseño de la investigación contempla la exploración documental y un estudio de campo. La primera aborda la evolución histórica para comprender el problema; igualmente se explora la normatividad en cuanto al uso del suelo y la evolución política del territorio de Usme. El estudio de campo se basa en el reconocimiento visual del territorio, donde se ratifican los problemas de sostenibilidad y se evidencia el deterioro ambiental ocasionado por la extracción minera, agricultura no sostenible y la conurbación.

También se aplican entrevistas semiestructuradas a una muestra compuesta por dos grupos de familias: unas oriundas del territorio y las otras, familias asentadas en Usme por motivos ajenos a su voluntad, como desplazamiento, reinserción o movidos por la búsqueda de mejores condiciones de vida.

\subsection{Hallazgos de la revisión de fuentes documentales}

\subsubsection{Sostenibilidad del territorio}

En el contexto geográfico, económico, social y ambiental de la localidad de Usme, como objeto de estudio, se enfatiza en la problemática de sostenibilidad del territorio y en la oportunidad que se tendría con el turismo de naturaleza como actividad económica para mejorar dicha situación. Estos hallazgos se relacionan a continuación:

Usme es la localidad más extensa del Distrito Capital de Bogotá, con un total de 21.556 hectáreas. El territorio se distribuye así: el $85 \%$ es área rural, el 10\% es el casco urbano de Usme y el 5\% es área de expansión urbana de la metrópoli. Por otra parte, 9.939 hectáreas $(46.1 \%)$ son área protegida por la fragilidad de los ecosistemas 
o por interés cultural (Alcaldía Mayor de Bogotá, 2000; León, 2013; Secretaría de Cultura, 2016).

El convulsionado devenir histórico del territorio ha suscitado cambios que ayudan a explicar la situación del territorio. 1- Época prehispánica: habitado por la comunidad aborigen Mhuysqa hace más de 1.500 años (Cardozo, 2014); 2- Época de la Conquista y la Colonia: se funda el pueblo con el nombre de San Pedro de Usme cuya toponimia proviene del nombre de una indígena llamada Usminia ligada a los romances de los caciques de la época (Químbayo, 2012; Zambrano, 2005); 3- Época de la República: en 1911 obtiene su autonomía como municipio. En 1954 se crea el Distrito Especial de Bogotá y el municipio de Usme es anexado como una localidad. En la segunda parte del siglo XX, se agudiza el conflicto armado que obligaba a los campesinos a emigrar hacia las grandes urbes y sus alrededores por lo que Usme acoge a un apreciable volumen de población desplazada y reinsertada, generando problemas sociales y empujando la frontera agrícola hacia tierras de páramo, lo cual deteriora los frágiles ecosistemas hasta hacerlos improductivos y áridos (Díaz et al., 2014; Zambrano, 2005) y 4- Época Actual: dada su cercanía a la metrópolis, se han agudizado progresivamente los problemas de conurbación y se han incrementado las actividades mineras (extracción de recebo para la construcción) con el consecuente deterioro ambiental.

\subsubsection{Potencial turístico}

Dentro de la oferta de turismo de naturaleza se tienen los siguientes espacios ecológicos catalogados como área protegida (Alcaldía Mayor de Bogotá, 2000, 2004, 2011; Díaz et al., 2014; Químbayo, 2012):

- El Parque Ecológico Distrital Entrenubes, Cuchilla del Gavilán y Cerro de Juan Rey, es el principal producto turístico y reúne la fauna y la flora propias del páramo.

- Reserva forestal protectora Bosque Oriental de Bogotá, área protegida de interés nacional y regional.

- El Agroparque Los Soches; corredores de restauración La Requilina, Yomasa Alta, Piedra Gorda y Aguadita- La Regadera; quebradas de Santa Librada, Yomasa, Fucha, Chuniza y Bolonia; áreas de restauración El Boquerón, Los ArbolocosChingaza y subpáramo Olarte; páramo Los Salitres; río Tunjuelito y Laguna de Bocagrande.

El patrimonio cultural está representado por la Estación del Tren en la vereda la Requilina de Usme, es una reliquia arquitectónica y en el casco urbano, según la Alcaldía Mayor de Bogotá (2004), hay 14 inmuebles de interés cultural, de éstos tres se consideran "Conservación Integral", es decir, que sus valores culturales son representativos de la memoria cultural de la ciudad y 11 inmuebles se clasifican como "Conservación Tipológica", representativos de la tipología arquitectónica de la época en que fueron construidos. Recientemente, en el año 2007, se hizo un importante descubrimiento arqueológico de un cementerio indígena de más de 2000 años de 
antigüedad, en la hacienda el Carmen de la vereda la Requilina, el cual tiene un incalculable valor histórico y cultural (Castro, 2014).

En cuanto a los emprendimientos turísticos, los graves problemas sociales que amenazan la seguridad del entorno han impedido su viabilidad debido al precario desarrollo económico del territorio, aspecto considerado como una variable mediadora que influye directamente a los dos eventos de estudio: la falta de arraigo de muchos de los habitantes no oriundos y la débil cohesión social, aspectos que se convierten en una constante amenaza de convivencia, tanto para la misma comunidad, como para los turistas (Burgos Doria, 2016; Camacho, 2016; Castiblanco, 2016; Castro, 2014; Zambrano, 2005). Esto se corrobora por dos estudios realizados por la Alcaldía Mayor de Bogotá que muestran las siguientes cifras (Alcaldía Mayor de Bogotá, 2010, p.46; Secretaría de Cultura, 2016, p.1): "el 98\% de la población está categorizada en estrato medio bajo (estratos 1, 2 y 3 ), de los cuales el $29,1 \%$ y el $5,3 \%$ se encuentran en condiciones de pobreza y pobreza extrema por ingresos, respectivamente" 8 . Además, Usme se ha catalogado como la "localidad número 8 respecto a mayores índices de delitos de impacto social".

\subsection{Hallazgos del estudio de campo}

\subsubsection{Instrumento de medición}

A partir de los eventos de estudio, como lo proponen Zapata y Hernández (2017), Ramírez (1991) y Hurtado (2012), se identifican las sinergias o dimensiones ${ }^{9}$ y de éstas se desprenden los indicios que derivan en las preguntas orientadoras del instrumento de medición para cada evento, como se aprecia en las tablas de especificaciones (tablas 1 y 2). Los instrumentos de medición se someten a validación de contenido ${ }^{10}$ mediante la técnica de validación por expertos.

Para este propósito se acude a 7 expertos, obteniendo para el evento 1 el $100 \%$ de concordancia entre los jueces y para el evento 2 el $92,6 \%$ de concordancia por lo que dos indicios fueron reubicados en la sinergia 2.1. En cuanto a la evaluación general de los instrumentos, se hizo con los siguientes criterios: congruencia ítem- dimensión; amplitud de contenidos; redacción de los ítems; precisión de los ítems; ortografía y presentación. El promedio de calificación fue el siguiente: evento 1- Aceptable 33\% y Excelente el 67\% y para el evento- 2, Aceptable el 26\% y Excelente el 74\%. Ningún juez consideró la opción Deficiente.

Tabla 1. Tabla de especificaciones primer evento. Cohesión social.

\footnotetext{
${ }^{8}$ Encuesta Multipropósito de Bogotá 2014 Alcaldía Mayor de Bogotá (2010).

${ }^{9}$ Los eventos pueden tener diferentes grados de complejidad, por lo que pueden dividirse en otros más específicos llamados sinergias o también conocidas como dimensiones (Hurtado, 2012).

${ }^{10} \mathrm{La}$ validación de contenido permite identificar el grado en que el instrumento mide los contenidos y contextos del evento de estudio (Hurtado, 2012).
} 
Evento 1-Cohesión social. Etimológicamente el vocablo cohesión proviene del latin cohaestum (adherirse o reunirse) y en el contexto del territorio se refiere al 1 grado de consenso entre los habitantes. La comunidad comparte intereses comunes, se suplen las necesidades del colectivo generando un alto grado de cohesión (Camacho, 2016).

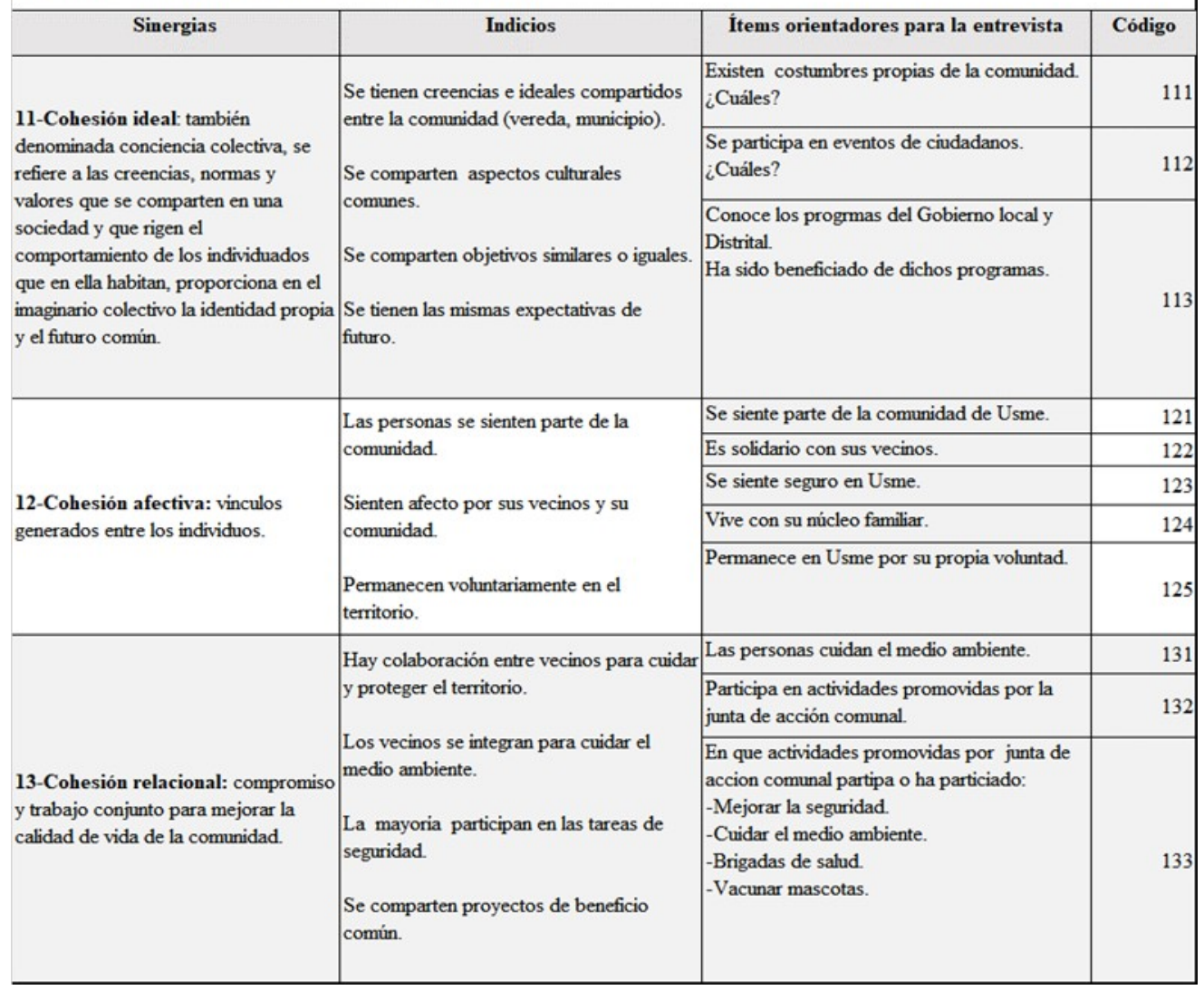

Fuente: elaboración propia.

La cohesión social es un concepto integral que abarca las perspectivas descritas en la tabla 1, dicho concepto se subdivide 3 sinergias o dimensiones: cohesión ideal, afectiva y relacional. 


\section{A continuación, en la Tabla 2 se especifica el evento 2. Arraigo territorial.}

Tabla 2. Tabla de especificaciones segundo evento. Arraigo territorial.

Evento 2-Arraigo territorial. Se deriva de la expresión echar raíces, es decir que la persona crea lazos culturales y afectivos que lo mantienen atado a un lugar determinado. En este caso la permanencia del individuo en el espacio geográfico (hábitat) es voluntario y normalmente viene determinado por el origen de sus ancestros y sus allegados donde se comparten las mismas reglas o normas y principios o valores y derivan su sustento en la comunidad o muy cerca de ella (Orduna, 2012).

\begin{tabular}{|c|c|c|c|}
\hline Sinergias & Indicios & Ítems orientadores para la entrevista & Código \\
\hline \multirow{6}{*}{$\begin{array}{l}\text { 21-Arraigo espacial, el individuo se } \\
\text { establece en un territorio fisicamente y } \\
\text { de manera voluntaria. El territorio } \\
\text { ofrece las oportunidades de desarrollo } \\
\text { humano, incluyendo el sustento. }\end{array}$} & \multirow{6}{*}{$\begin{array}{l}\text { Tienel sentido de pertenecia y } \\
\text { defiende el territorio. } \\
\text { También se relaciona con la } \\
\text { inclusión social. } \\
\text { La cantidad de tiempo que tienen } \\
\text { viviendo en el territorio de Usme. }\end{array}$} & Cuánto tiempo lleva viviendo en Usme. & 211 \\
\hline & & Vive con su familia en Usme. & 212 \\
\hline & & Deriva su sustento dentro del territorio de Usme o no. & 213 \\
\hline & & Tiene estudio para usted y su familia en Usme. & 214 \\
\hline & & $\begin{array}{l}\text { Participa en las acciones que hace la comunidad para impedir } \\
\text { el cambio de uso del suelo. }\end{array}$ & 215 \\
\hline & & $\begin{array}{l}\text { Trabajaria en turismo de naturaleza en Usme como: } \\
\text { - Guia turistico. } \\
\text { - Adecuando su finca para el turismo. } \\
\text { - Elaborando productos autóctonos. } \\
\text { - En gastronomia típica. } \\
\text { - Otros. }\end{array}$ & 216 \\
\hline \multirow{6}{*}{$\begin{array}{l}\text { 22-Arraigo cultural, por la necesidad } \\
\text { humana de creer en valores, principios } \\
\text { y normas. Se comparte la misma } \\
\text { cosmovisón. }\end{array}$} & \multirow{4}{*}{$\begin{array}{l}\text { Hay una interacción de la } \\
\text { comunidad con el lugar. } \\
\text { Las persona se siente parte de la } \\
\text { historia en el contexto del } \\
\text { entorno y valoran su patrimonio } \\
\text { histórico. }\end{array}$} & $\begin{array}{l}\text { Conoce el potencial natural y cultura que tienen en la } \\
\text { localidad. }\end{array}$ & 221 \\
\hline & & $\begin{array}{l}\text { Sigue y mantiene las costumbres gastronómicas propias del } \\
\text { territorio. }\end{array}$ & 222 \\
\hline & & Conoce la historia del territorio y se siente parte de ella. & 223 \\
\hline & & $\begin{array}{l}\text { Conoce los simbolos de Usme (escudo, himno, bandera, } \\
\text { entre otros). Cuáles simbolos conoce? }\end{array}$ & 224 \\
\hline & \multirow{2}{*}{$\begin{array}{l}\text { Existe significado y simbolismo } \\
\text { compartidos (artes, deportes, } \\
\text { gastronomia, etc.) }\end{array}$} & $\begin{array}{l}\text { Visita el Páramo como esparcimiento y reconocimiento de la } \\
\text { riqueza natural. }\end{array}$ & 225 \\
\hline & & Conoce y/o visita los descubrimientos arqueológicos. & 226 \\
\hline \multirow{3}{*}{$\begin{array}{l}\text { 23-Arraigo social, porque se } \\
\text { relaciona con otras personas y forma } \\
\text { parte de grupos sociales para la } \\
\text { defensa del territorio. }\end{array}$} & \multirow{3}{*}{$\begin{array}{l}\text { Siente afecto por sus vecinos y } \\
\text { su comunidad. } \\
\text { Permanece de forma voluntaria } \\
\text { en el territorio }\end{array}$} & Ha sido discriminado por su condición social. & \\
\hline & & $\begin{array}{l}\text { Ha resultado favorecido por los programas que adelanta el } \\
\text { Distrito o las Universidades. }\end{array}$ & 232 \\
\hline & & $\begin{array}{l}\text { Tiene vivienda propia en Usme. Ha sido beneficiado con los } \\
\text { programas de vivienda de interés prioritario del Gobiero } \\
\text { Nacional. }\end{array}$ & \\
\hline
\end{tabular}

Fuente: Elaboración propia.

Como se aprecia en la tabla 2, el concepto de arraigo territorial para este estudio se subdivide en 3 sinergias o dimensiones: arraigo espacial, cultural y social. Tanto el arraigo territorial como la cohesión social se consideran vitales para el éxito del turismo, aspecto que cobra relevancia para el caso colombiano dados los problemas de desplazamientos forzados generados por más de medio siglo de conflicto interno. 


\subsubsection{Resultados del estudio de campo}

\section{El resultado del estudio de cohesión social se resume en la tabla 3.}

Tabla 3. Resultados del estudio de cohesión social.

\begin{tabular}{r|l|}
\hline \multicolumn{1}{|c|}{ Código } & \multicolumn{1}{|c|}{ Análisis items orientadores. Cohesión Colectiva } \\
\hline 111 & $\begin{array}{l}\text { Las personas oriundas afirman que una de las costumbres más arraigadas es hacer caminatas al pueblo, donde consumen } \\
\text { comidas tipicas de la cultura campesina. }\end{array}$ \\
\hline 112 & $\begin{array}{l}\text { El } 40 \% \text { de las personas oriundas entrevistadas han participado en algunos eventos sobre todo los relacionados con } \\
\text { esparcimiento como caminatas organizadas por las autoridades locales. Pero el } 60 \% \text { de la población oriunda y la totalidad de } \\
\text { los que no lo son nunca han participado en estos eventos ciudadanos. }\end{array}$ \\
\hline 113 & $\begin{array}{l}\text { Solo el } 20 \% \text { de las personas oriundas entrevistadas conocen los programas del Gobierno local y Distrital y han sido } \\
\text { beneficiados con algunos de ellos, mientras que el } 80 \% \text { de ellas y la totalidad de las personas no oriundas no los conocen. }\end{array}$ \\
\hline
\end{tabular}

ANÁLISIS. La cohesión colectiva en la comunidad es relativamente baja. Se puede estimar que algo más del $20 \%$ de los pobladores oriundios comparten realmente valores y normas, mientras que ninguno de los pobladores que no son oriundos de la región lo hace. Esto impide que haya en el imaginario colectivo un sentido de identidad propia y de futuro común.

\begin{tabular}{|c|c|}
\hline Código & Análisis items orientadores. Cohesión Afectiva \\
\hline 121 & $\begin{array}{l}\text { Todas personas oriundas y un tercio de los no oriundos, se sienten parte de la comunidad y les gusta vivir alli. Pero dos } \\
\text { tercios de las personas no oriundas no se sienten parte de la comunidad. }\end{array}$ \\
\hline 122 & $\begin{array}{l}\text { Todas las personas oriundas y dos terceras partes de las que no lo son, manifiestan ser solidarias con sus vecinos y ayudan a } \\
\text { otros cuando lo requieran. Solo un tercio de las personas no oriundas no son solidarias, aduciendo falta de tiempo. }\end{array}$ \\
\hline 123 & $\begin{array}{l}\text { E1 } 80 \% \text { de los habitantes oriundos se sienten seguros y han aprendido a convivir con los problemas de inseguridad, pero el } \\
100 \% \text { de las personas no oriundas del territorio se sienten inseguras, especialmente en horas de la noche. }\end{array}$ \\
\hline 124 & $\begin{array}{l}\text { Todas las personas oriundas y dos terceras partes de las que no lo son manifiestan estar en la localidad por su propia } \\
\text { voluntad, aunque las personas no oriundas se irian de Usme si se les presenta la oportunidad para estar más cerca de su }\end{array}$ \\
\hline \multicolumn{2}{|r|}{$\begin{array}{l}\text { ANÁLISIS. La cohesión afectiva dentro de la comunidad es relativamente alta. Más del } 80 \% \text { de los pobladores oriundos y foráneos } \\
\text { mantienen vinculos personales y de solidaridad. Sin embago, como es de esperarse, la población no oriunda establece menores vinculos } \\
\text { afectivos con sus vecinos y todos ellos manifiestan sentirse inseguros en la comunidad, especialmente en horas de la noche. }\end{array}$} \\
\hline Código & Análisis items orientadores. Cohesión Relacional \\
\hline 131 & $\begin{array}{l}\text { Todos los entrevistados (oriundos y no oriundos) coinciden en que las personas no cuidan el medio ambiente y que el } \\
\text { problema más grave es el manejo de basuras, lo cual genera malos olores y la proliferación de ratas e insectos. }\end{array}$ \\
\hline 132 & $\begin{array}{l}\text { En cuanto a la particpación en actividades de la Junta de acción comunal, el } 60 \% \text { de las personas oriundas participan o han } \\
\text { participado en algunas de ellas, pero el resto de esta población junto con la totalidad de la no oriunda nunca lo ha hecho. }\end{array}$ \\
\hline 133 & El $40 \%$ de las personas oriundas participan en actividades de seguridad. Pero ninguno de los entrevistados no oriundos, lo \\
\hline \multicolumn{2}{|r|}{$\begin{array}{l}\text { ANÁLISIS. La cohesión relacional muestra marcadas diferencias entre los dos grupos de pobladores. Mientras que en las personas } \\
\text { oriundas cerca del } 50 \% \text { tienen compromiso de trabajo para mejorar la calidad de vida de la comunidad, las personas foráneas no lo } \\
\text { tienen en absoluto. Todos coinciden que la falta de conciencia ambiental es un problema grave, sobre todo, con el manejo de las basuras }\end{array}$} \\
\hline
\end{tabular}

Fuente: Elaboración propia.

En la tabla 3, se aprecia que en las tres sinergias de cohesión social (ideal, afectiva y relacional), hay diferencias entre las percepciones de los dos grupos de familias entrevistadas siendo, como se esperaba, más fuerte la cohesión de las familias oriundas. Se resalta que la cohesión afectiva es alta, es decir, que hay un fuerte lazo familiar. En las familias foráneas la cohesión colectiva y relacional es muy débil, lo que era de esperar porque el $99,95 \%$ de los habitantes de la localidad son foráneos, como lo mencionan León (2013) y Secretaría de Cultura (2016). 


\section{En la tabla 4, se muestran los hallazgos del evento de arraigo territorial.}

\section{Tabla 4. Resultados del estudio de arraigo territorial.}

\begin{tabular}{|c|c|}
\hline Código & Análisis items orientadores. Arraigo Espacial \\
\hline 211 & Los habitantes oriundos entrevistados llevan en la localidad en promedio 37 años, mientras que los no oirundos han estado alli en promedio 3 años. \\
\hline 212 & Todas las personas entrevistadas (oriundas y no oriundas) conviven con su nucleo familiar y en el $80 \%$ de los casos conviven hasta tres generaciones. \\
\hline 213 & $\begin{array}{l}\text { Todas las familias oriundas derivan su sustento total o parcialmente en la localidad, con actividades sencillas como manejar taxi, vender chance, trabajar } \\
\text { el campo y solo en un caso, se realizan actividades de turismo en la Ruta la Requilina. Esto contrasta con las familias no oriundas quienes no derivan nada } \\
\text { de sustento en la localidad. }\end{array}$ \\
\hline 214 & Todos afirman que solo hay estudio para los niños pequeños y hasta el bachillerato, lo cual no es suficiente. \\
\hline 215 & $\begin{array}{l}\text { Solo el } 20 \% \text { de los entrevistados oriundos manifiestan haber participado en dichas acciones, aunque todos estan de acuerdo con las acciones para } \\
\text { impedir el cambio de uso del suelo. En cuanto a la población no oriunda, ninguno se ha enterado del problema y no le interesa participar. }\end{array}$ \\
\hline$\left.216\right|_{f}$ & $\begin{array}{l}\text { A todos los entrevistados (oriundos y no oriundos) les gustaria trabajar en turismo, sobre todo si esto significa un mejor ingreso para mantener a su } \\
\text { familia. }\end{array}$ \\
\hline $217 \mid$ & $\begin{array}{l}\text { E1 } 60 \% \text { de los entrevistados oriundos y el } 30 \% \text { de los no oriundos ha visitado el páramo y lo consideran muy bonito. Los restantes nunca se han } \\
\text { interesado por hacerlo.. }\end{array}$ \\
\hline 218 & $\begin{array}{l}\text { Mientras que la totalidad de las personas oriundas entrevistadas tienen vivienda propia, ninguna de las personas no oriundas la tiene y solo el } 10 \% \text { de los } \\
\text { entrevistados han sido beneficiados con programas de subsidio de vivienda. }\end{array}$ \\
\hline $\begin{array}{l}\text { ANÁLISIS } \\
\text { vivienda pro } \\
\text { mediante act } \\
\text { derivan su su } \\
\text { 1- Todas las } \\
\text { 2- El estudio } \\
\text { 3- A la may } \\
\text { suelo del ter } \\
\text { 4- A todos } 1\end{array}$ & $\begin{array}{l}\text { S. El arraigo espacial es marcadamente diferente entre las poblaciones oriundas y las no oriundas. Las primeras tienen un arraigo fuerte al territorio, tienen } \\
\text { opia y derivan parcialmente su sustento en la localidad con actividades básicas; el } 20 \% \text { del grupo de estudio deriva todo su sustento en la localidad } \\
\text { ctividades agricolas y turisticas. Mientras que en las personas no oriundas, el arraigo espacial es notablemente débil, no tienen vivienda propia y no } \\
\text { sustento en la localidad (todos trabajan en la ciudad de Bogotá). Se resaltan los siguientes items: } \\
\text { as personas entrevistadas viven con su núcleo familiar. } \\
\text { io que se ofrece en la localidad solo cubre hasta el bachillerato y los jóvenes que quieren seguir estudiando migran a la ciudad de Bogotá. } \\
\text { yoria ( } 80 \% \text { de la población oriunda y } 100 \% \text { de los que no lo son), no les interesa y no han participado en acciones para impedir el cambio del uso del } \\
\text { erritorio hacia la urbanización y la explotación minera. }\end{array}$ \\
\hline
\end{tabular}

\begin{tabular}{|c|c|}
\hline Código & Análisis items orientadores. Arraigo Cultural \\
\hline 221 & $\begin{array}{l}\text { Menos de la mitad ( } 40 \% \text { ) de las personas oriundas afirma conocer algunos sitios atractivos, pero todos, incluyendo los no oriundos, desconocen el } \\
\text { patrimonio natural y cultural de la localidad. }\end{array}$ \\
\hline 222 & $\begin{array}{l}\text { Las personas oriundas conocen la cultura gastronómica basada costumbres campesinas del interior del pais y esporádicamente preparan dichos platos. } \\
\text { Esto constrasta con los no oriundos que la desconocen totalmente. }\end{array}$ \\
\hline 223 & $\begin{array}{l}\text { Solo las personas que trabajan directamente en turismo, Ruta la Requilina, conocen la historia (el } 20 \% \text { de los entrevistados), el resto indluyendo las } \\
\text { personas no oriundas, la desconocen. }\end{array}$ \\
\hline 224 & Ninguna de las personas entevistadas (oriundas y no oriundas) conoce los simbolos de la localidad. \\
\hline 225 & $\begin{array}{l}\text { Todos los entevistados (oriundos y no oriundos) saben de la existencia del cementerio indigena a través de las noticias, pero solo el } 20 \% \text { de los } \\
\text { habitantes oriundos ha participado en las protestas para impedir la urbanización de estos terrenos. }\end{array}$ \\
\hline \multicolumn{2}{|r|}{$\begin{array}{l}\text { ANÁLISIS. El arraigo cultural es bajo, en los pobladores oriundos y nulo en los foráneos. No se conoce la historia, ni los simbolos y solo el } 40 \% \text { de los pobladores } \\
\text { oriundos afirman conocer algunos atractivos turisticos y saben de los descubrimientos arqueológicos porque ha sido un tema ampliamente tratado en la prensa. Los } \\
\text { pobladores oriundos conocen la gastronomia y eventualmente la preparan en sus hogares. Cabe resaltar que las personas dedicadas al turismo, (10\%) de los } \\
\text { entrevistados, son las que más conocen la historia y los sitos y actividades culturales. }\end{array}$} \\
\hline Código & Análisis items orientadores. Arraigo Social \\
\hline 231 & Ninguna persona (oriunda o no oriunda) se siente discriminada en la localidad. \\
\hline 232 & $\begin{array}{l}\text { De las personas oriundas, solo el } 20 \% \text { ha utilizado los recursos ofrecidos por el Distrito y las Universidades para promover el turismo, es el caso de la } \\
\text { integrante de la Ruta la Requilina. Las personas no oriundas afirman no conocer estos programas y tampoco les interesa. }\end{array}$ \\
\hline \multicolumn{2}{|r|}{$\begin{array}{l}\text { ANÁLISIS. El arraigo social es diferente entre las personas oriundas y las foráneas. Las primeras se interesan más relacionarse entre si, pero solo un } 20 \% \text {, mientras } \\
\text { que las segundas no establecen lazos sociales en la localidad porque no tienen tiempo y solo van a Usme a pernoctar. De los entrevistados solo el } 20 \% \text { ha accedido } \\
\text { a recursos para emprendimientos en turismo. Se resalta que ninguna de las personas entrevistadas se ha sentido discriminada por su condición social. }\end{array}$} \\
\hline
\end{tabular}

Fuente: Elaboración propia. 
Los resultados del estudio de arraigo territorial consolidados en la tabla 4, reflejan que el arraigo espacial en los habitantes oriundos es fuerte, pero es casi nulo en los habitantes foráneos. Asimismo, los indicadores de arraigo cultural y de arraigo social son bajos en la población oriunda y muy bajos en la población foránea. Estos resultados alertan a todos los actores (públicos y privados) para diseñar y aplicar estrategias que conduzcan al mejoramiento de los indicadores de arraigo porque la mayoría de la población de Usme es foránea, como se ha indicado anteriormente.

\subsubsection{Observación directa}

Fruto de las observaciones sobre el terreno, las conversaciones y vivencias con las mujeres gestoras de la Ruta La Requilina, se encuentra lo siguiente:

- La Ruta no es rentable y se tiene como una actividad ocasional. Generalmente, el Instituto Distrital de Turismo organiza algunos eventos para llevar turistas a la ruta.

- Hay problemas personales dentro de las dueñas de las fincas, por desconfianza u otras actitudes derivadas de falta de cohesión.

- Hay problemas de seguridad para los visitantes debido a los conflictos sociales del territorio.

- Se presenta deterioro gradual de los recursos naturales y culturales por el saqueo del cementerio indígena, la conurbación, los asentamientos ilegales que no se han detenido, la presencia de minería ilegal y los conflictos sociales.

\subsection{Propuesta del modelo de turismo rural comunitario para la localidad de Usme}

El modelo propuesto es el resultado de varios estudios consecutivos desarrollados en la localidad, donde el eje central de las intervenciones es la consolidación de la cadena turística de Usme para ser articulada con la oferta turística de Bogotá, donde se precisa de la participación clara y coordinada de cuatro actores: comunidad, academia, empresa y Estado.

Dentro del modelo la cohesión social y el arraigo territorial son parte fundamental del eje de Desarrollo Sostenible del Territorio como dinamizadores del desarrollo económico, social y ambiental. La participación integrada de todos los actores es necesaria para sentar las bases de la cadena turística y para aprovechar la oportunidad de financiación de proyectos y de emprendimientos contemplados dentro de los programas del Gobierno nacional y distrital (Programa de Transformación Productiva, Programa para el Postconflicto, la Triada de la Competitividad- UEE (UniversidadEmpresa- Estado, entre otros.). En este escenario se favorecen los emprendimientos, los negocios y las microempresas que tengan origen en la iniciativa de la comunidad.

El modelo proporciona una visión global y de largo plazo para encadenar los esfuerzos de los diferentes actores hacia un fin común (consolidar la cadena turística de Usme) optimizando los recursos. El modelo de turismo rural comunitario y la relación entre los actores se esquematiza en la Figura 2. 
Figura 2. Modelo de turismo rural comunitario para la localidad e Usme.

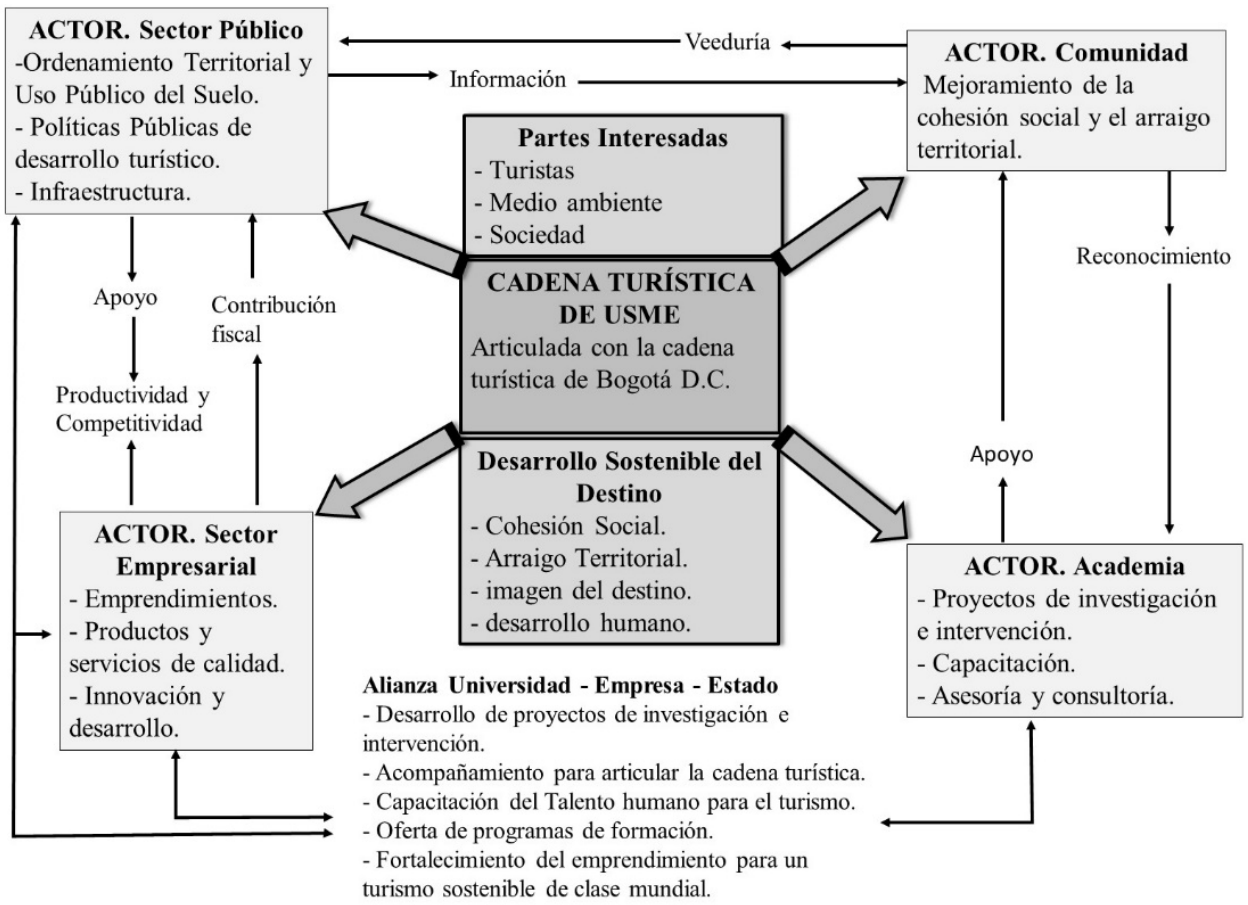

Fuente: Elaboración propia.

Para que el modelo de turismo rural comunitario sea sostenible debe contar con lo siguiente:

- Un proyecto de largo plazo, donde se garanticen los recursos humanos y económicos. Que no esté sujeto a las administraciones de turno, por lo que la mejor figura es la financiación a través de regalías u otra fuente externa a la Universidad. Dentro de los planes del Gobierno Nacional para financiar proyectos de intervención en territorios vulnerables (como es el caso de Usme), se tiene la Ley de regalías ${ }^{11}$ (Ley 1942, 2018). Los recursos se desembolsan mediante el concurso en convocatorias de proyectos de intervención presentados por los grupos de investigación adscritos a las Universidades o Centros de Investigación con alianzas con el sector empresarial, la comunidad y/o entidades públicas, según los requisitos de cada convocatoria.

${ }^{11}$ Autoriza recursos para las regiones por $\$ 24,2$ billones, durante el bienio 2019-2020, administradas por el Sistema General de Regalías (SGR). 
- Aprovechar otras fuentes de recursos provenientes del sector privado y de los recursos que aportan instituciones como: el Instituto Distrital del Turismo, la Alcaldía Mayor de Bogotá, La alcaldía local de Usme, las universidades, entre otras fuentes de financiamiento.

- Hacer intervenciones sociales para fortalecer el arraigo y la cohesión social. Como se ha demostrado dentro de esta investigación, estos elementos son indispensables para iniciar un proyecto turístico.

- Incluir a todos los actores como se muestra en la figura 2. Esto permite que se aúnen esfuerzos para potenciar los resultados. Así, se pueden coordinar eficazmente los emprendimientos y gestionar los recursos para maximizar los beneficios.

- Estar alineado con las políticas pública nacionales, distritales y locales, sin perder de vista el enfoque global, para aprovechar las oportunidades de financiamiento de los emprendimientos.

\section{Conclusiones y consideraciones finales}

Se han realizado acciones por varias entidades (Instituto Distrital de Turismo, Universidades, Alcaldía Menor de Usme, Alcaldía Mayor de Bogotá, entre otros.)-con inversiones apreciables. Pero dichas acciones no han tenido el impacto esperado porque se hacen de forma dispersa y no están sujetas a un programa a largo plazo que trascienda las administraciones de turno y tenga continuidad en el tiempo, sobre todo, que tengan en cuenta los intereses de los habitantes. Los resultados muestran que la mayoría de los habitantes $(95 \%)$ tienen problemas de cohesión social y arraigo al territorio-dadas las circunstancias de desplazamiento y reinserción, lo cual debiera ser prioritario de atender antes de los proyectos de emprendimiento productivo, aspecto ratificado por Castiblanco (2016) y Gómez (2010).

Lo anterior impide que se aproveche el gran potencial turístico de la localidad y la oportunidad de acceder a un mercado turístico de alta capacidad de pago, ya que Bogotá acoge al 69\% de extranjeros no residentes que vienen al país para eventos, negocios y motivos profesionales, turistas que en el fin de semana y tiempo libre serían la potencial demanda del turismo de naturaleza para Usme dada su cercanía a la ciudad de Bogotá.

Con respecto al grupo de mujeres campesinas que lideran la Ruta Turística la Requilina, aunque tienen arraigo, no han logrado organizarse eficazmente por falta de cohesión, especialmente cohesión colectiva y cohesión relacional, surgiendo muchas disputas personales que no se resuelven, por lo que se requiere un acompañamiento por parte de la academia y el sector público con estrategias de sensibilización y capacitación para superar la envidia, el protagonismo y la desconfianza entre el grupo y que les permita asociarse para impulsar el bien común en todos los ámbitos.

En este escenario, la comunidad local, como actor determinante, ejerce un alto impacto para el éxito del turismo en cualquiera de sus modalidades, pero muy especialmente en el de naturaleza. Pérez, Zizumbo y Monterroso (2009, p. 50) corroboran este argumento en el estudio sobre la resistencia y defensa del territorio en 
el parque natural Nevada de Toluca- México, donde proponen "la obligatoria consideración de los intereses de los grupos locales, durante las etapas de planeación e integración de cualquier tipo de emprendimiento turístico, pues constituyen el actor fundamental para el adecuado desarrollo del mismo".

Así pues, construir destinos turísticos sostenibles es un reto que tiene muchas variables para contemplar por ser un sector interdisciplinario, donde intervienen varios actores articulados para obtener resultados sostenibles que impulsen el desarrollo del territorio, porque puede convertirse en una actividad depredadora y contaminante-si no se planifica adecuadamente. Además, no basta con tener el patrimonio natural y cultural, hay que ponerlos en valor para volverlos productos turísticos y debe existir una planificación de uso del suelo y carga del destino para no acabar dicho patrimonio, que en el caso colombiano se ha preservado, entre otras cosas por el mismo conflicto armado que mantuvo muchos de estos escenarios vetados para el turismo.

Ahora bien, el modelo propuesto en este estudio debe ser de largo plazo e integrador con proyectos parciales. Además, puede ser replicado en otras regiones del país especialmente en aquellos espacios rurales cercanos a grandes ciudades, en el marco de Ciudad-Región como foco dinamizador del turismo receptivo.

\section{Referencias bibliográficas}

Alcaldía Mayor De Bogotá. (2000). Decreto Distrital 619 de 2000: POT-Bogotá 2000. Bogotá D.C.: Alcaldía Mayor de Bogotá.

Alcaldía Mayor De Bogotá. (2004). Decreto 190 de 2004: Revisión POT- Bogotá 2004. Bogotá D.C.: Alcaldía Mayor de Bogotá.

Alcaldía Mayor De Bogotá. (2007). Decreto 327 de 2007: Política Ruralidad Distrital. Bogotá D.C.: Alcaldía Mayor de Bogotá.

Alcaldía Mayor De Bogotá. (2010). Localidad Usme: diagnóstico local de salud con participación social 2009-2010 enero de 2010. 1-426. Disponible en https://cutt.ly/xrUufh3

Alcaldía Mayor De Bogotá. (2011). Monografía Localidad de Usme 2011. Alcaldía Mayor de Bogotá. Disponible en https://cutt.ly/WrUub9W

Alto Comisiondo Para La Paz. (2016). Acuerdo final para la terminación del conflicto y la construcción de una paz estable y duradera. Bogotá D.C. Presidendencia de la República. Disponible en https://www.cancilleria.gov.co/sites/default/files/Fotos2016/12.11_1.2016nuevoacuerdofin al.pdf

Asamblea General De Naciones Unidas. (2003). Memoria del Secretario General sobre la labor de la Organización. Disponible en https://cutt.ly/BrUuSLL

Benavides, G. F. (2015). Las políticas públicas del turismo receptivo colombiano. Suma de Negocios. vol. 6, no 13, 66-73. Disponible en https://doi.org/10.1016/j.sumneg.2015.08.005 
Berger, R. (2000). Social cohesion as an aspect of the quality of societies: concept and measurement. EuReporting Working Paper, 14, 1-31. Disponible en https://cutt.ly/YrUu9Ij

Burgos, R. (2016). El turismo comunitario como iniciativa de desarrollo local. Caso localidades de Ciudad Bolívar y Usme zona rural de Bogotá. Hallazgos, vol.13, no 26. Disponible en https://cutt.ly/1yjB1x5

Camacho, A. (2016). A expansão urbana como reveladora de territorialidades: conflito de proximidade em Usme-Bogotá. Revista Eletrônica Do Centro Interdisciplinar de Estudos Sobre a Cidade, vol. 8, no 3, 133-148. Disponible en https://doi.org/10.20396/urbana.v8i3.8646409

Cardozo, A. T. (2014). Patrimonio y memoria: encuentros y desencuentros por el hallazgo del cementerio muisca en la hacienda El Carmen, en Bogotá, D. C. Campos en Ciencias Sociales, vol. 2, no 2, 207-223. Disponible en https://cutt.ly/LrUpqc1

Castiblanco, S. E. (2016). Capacidad empresarial femenina en Situación de Desplazamiento forzado: El caso de Usme en Bogotá. Suma de Negocios, vol. 7 no 15, 61-72. Disponible en https://doi.org/10.1016/j.sumneg.2016.02.004

Castro, A. (2014). La Hacienda El Carmen como escenario coyuntural de disputa sobre memoria, territorio y patrimonio. Campos En Ciencias Sociales, vol. 2 no 2, 179-205. Disponible en https://cutt.ly/gyjBZ08

Cebrián, F., \& García, J. A. (2016). Turismo rural y paisaje en zonas de montaña. Propuesta metodológica para identificar sus relaciones en las Sierras Meridionales de la Provincia de Albacete. Anales de Geografia de La Universidad Complutense, 36(2), 237-257. Disponible en https://doi.org/10.5209/AGUC.53584

CEPAL. (2007). Cohesión social: inclusión y sentido de pertenencia en América Latina y el Caribe. Naciones Unidas - CEPAL. Disponible en https://cutt.ly/trUikDB

CERAC - PNUD. (2014). ¿Qué ganará Colombia con la paz?. Centro de Recursos para el anális de conflictos. Disponible en https:/cutt.ly/0rUpLAB

Cerda, L. y Leguizamón, M. (2005). Análisis del comportamiento de la demanda turística urbana en Colombia. Anuario Turismo y Sociedad, vol. 4, 70-98. Disponible en: https://cutt.ly/PrUp6OS

Díaz, O., Garzón, J. C., Medina, S. L., Mendoza, A., Quijano, D. M., et.al. (2014). El Agroparque Los Soches como estrategia de consolidación del borde sur de Bogotá. Universidad Nacional de Colombia. Disponible en: https://cutt.ly/krUayL9

Ellis, S. (2011). Community Based Tourism in Cambodia: Exploring the role of community for successful implementation in Least Developed Countries. Published doctoral thesis. Edith Cowan University. Disponible en https://ro.ecu.edu.au/theses/451/

Fernández, A. y Martínez, H. (2017). El Acceso a Los Destinos Rurales: Una Perspectiva Para La Planificación Territorial Del Turismo En Una Región De Interior (Castilla-La Mancha ). Cuadernos de Túrismo, 40, 251-272. Dipoinible en https://doi.org/10.6018/turismo.40.309691

Gómez, J. A. (2010). Turismo, conflicto armado y paz en Colombia: Apostándole al futuro. Anuario Turismo y Sociedad, vol.1, 57-69. 
González, M. e Iglesias, G. (2009). Impactos del turismo sobre los procesos de cohesión social Caibarién, Cuba. Estudios y Perspectivas En Turismo, vol. 18, 53-68. Disponible en: https://cutt.ly/8rUstSb

Hurtado, J. (2012). Metodología de la investigación: Guía para la comprensión holística de la ciencia. $4^{\mathrm{a}}$. Ed. Bogotá- Caracas: Ediciones Quirón.

Kieffer, M. (2016). La cohesión social: Elementos de análisis comparativo de dos iniciativas de Turismo Rural Comunitario en Chiapas, México. Ecología Política, vol. 52, 69-73. Disponible en https://cutt.ly/xrUsfV1

Langebeck, E. y Beltrán, J. E. (2016). Sustentabilidad territorial de los procesos de ocupación urbano- rurales en Usme, Bogotá - Colombia. Gestión y Ambiente, vol 19, no 1. Disponible en: https://cutt.ly/xrUsxnR

León, J. C. (2013). Plan Ambiental Local-PAL: localidad Usme. Bpgptá. D.C.: Alcaldía Local de Usme. Disponible en https://cutt.ly/3rUsUyc

Ley 1942. (diciembre 27 de 2018). Por la cual se decreta el presupuesto del Sistema General de Regalías para el bienio del $1^{\circ}$ de enero de 2019 al 31 de diciembre de 2020. Bogotá: Diario oficial. n. 50819

López, A. L. (2013). Modelo de turismo sustentable en Suesca - Cundinamarca como área protegida. Tesis doctoral publicada en Tesis Doctorales - TESEO. Disponible en http://gredos.usal.es/jspui/handle/10366/124175\%0A

López, A. L.y López, S. A. (2018). Impacto de Las TIC en El Turismo: Caso Colombiano". Cuadernos de Turismo, vol. 41, 399-418. Disponible en https://doi.org/http://dx.doi.org/10.6018/turismo.41.327081

Lorenzo, H.y Morales, G. (2014). Del desarrollo turístico sostenible al desarrollo local. Su comportamiento complejo. Revista de Turismo y Patrimonio Cultural, vol 12 no 2. Disponible en: https://www.redalyc.org/pdf/881/88130205003.pdf

MinCIT. (2014). Plan Sectorial de Turismo 2014 - 2018. Turismo para la construcción de la paz. Bogotá D.C: Ministerio de Comercio, Industria y Turismo. Disponible en https://cutt.ly/grUdzAF

MinCIT y PTP. (2013). Plan de Negocio de Turismo de Naturaleza de Colombia . Bogota D.C.:Ministerio de Comercio, Industria y Turismo. Disponible en https://cutt.ly/ArUd05h

Nieto, A. (2013). Participación Comunitaria en iniciativas de ecoturismo en la Vereda Los Soches, localidad de Usme, Bogotá. Revista Interamericana de Ambiente y Turismo. Disponible en http://riat.utalca.cl/index.php/test/article/view/254

OMT. (1995). Carta del Turismo Sostenible. Santa Cruz de Tenerife: TENYDEA S.L.

OMT. (2015). La contribución del Turismo a los Objetivos del Desarrollo Sostenible. Organización Mundial del Turismo. Disponible en https://cutt.ly/nrUfo3f

ONU. (2015). El Pacto Mundial de las Naciones Unidas: una llamada a la acción para empresas sostenibles. Organización de las Naciones Unidas. Disponible en https://goo.gl/C4ENLr

ONU y UNWTO. (2001). Código ético mundial para el turismo: por un turismo responsable. Organización de las Naciones Unidas y Organización Mundial del turismo. Disponible en https://cutt.ly/qrUfbNg

Orduna, M. G. (2012). Identidad e identidades: Potencialidades para la cohesión social y territorial. Barcelona: Urb-al III. Disponible en https://www1.diba.cat/uliep/pdf/52259.pdf 
Pérez, C.y Zizumbo, L. (2014). Turismo rural y comunalidad: Impactos socioterritoriales en San Juan Atzingo, México. Cuadernos de Desarrollo Rural, vol.11, no 73, pp. 17-38. Disponible en https://doi.org/10.11144/Javeriana.CDR11-73.trci

Pérez, M. A. y Rojas, J. (2008). Desarrollo Sostenible: Principios, aplicaciones y lineamientos de política para Colombia. Cali-colombia: Universidad Del Valle - Instituto Cinara. Disponible en https://cutt.ly/WrUf736

Pérez, S. (2010). El valor estratégico del turismo rural como alternativa sostenible de desarrollo territorial rural. Agronomía Colombiana., vol. 28, no 3, pp. 507-513. Disponible en https://revistas.unal.edu.co/index.php/agrocol/article/view/14688

Procolombia. (2018). Informe de gestión 2018. Procolombia. Disponible en https://cutt.ly/wrUgr4A

Químbayo, G. A. (2012). Parque Entrenubes: Ciudad , conservación y movimientos sociales al sur de Bogotá. HALAC, vol, II, $\mathrm{n}^{\mathrm{o}}$ 2, 24-46. Disponible en https://halacsolcha.org/index.php/halac/article/download/186/181/

Ramírez, M.y García, M. (2010). La Alianza Universidad- Empresa-Estado: una estrategia para promover innovación. Revista EAN, vol. 68, 112-133. Disponible en https://cutt.ly/wrUgaed

Ramírez, T. (1997). Construcción y Validación de una Escala para Medir los Niveles de Satisfacción Laboral de los Docentes de Educación Básica en Venezuela. Revista de Investigación y Postgrado. Vol. XII, no 2, 167-190. ISSN: 0798-9792

Sotelo Pérez, I., Sotelo Pérez, M. y Sotelo Navalpotro, J.A. (2020). Una aproximación a las Políticas y actuaciones del saneamiento de las aguas residuales, en España. M+A, revista electrónica de medioambiente, ISSN-e 1886-3329, Vol. 21.1, págs. 122-158

Secretaría de Cultura. (2016). Ficha local Usme. Diciembre 14 de 2016. Alcaldía Mayor de Bogotá. Disponible en https://cutt.ly/ArUgdc4

Universidad Diego Portales. (2009). Cohesión Social y Recuperación de Barrios: Una mirada de los Consejos Vecinales de Desarrollo de la Región Metropolitana. Cuadernos de Barrio, no 2, 1-33. Disponible en https://cutt.ly/rrUgzRx

Zambrano, F. (2005). Usme: urbanizacion y cambios en la vida urbana en (CCB, 2005). Pasado, presente y futuro de la localidad de Usme,. 9-40. Bogotá: Cámara de Comercio de Bogotá. Disponible en https://cutt.ly/mrUgWuM

Zapata, G.J. y Hernández, A. (2017). Escala de medición de la percepción gerencial y directiva del entorno empresarial. Revista de Ciencias Sociales. vol. XXIII, no 2, 84-99. Disponible en: https://www.redalyc.org/pdf/280/28056733007.pdf. 